\title{
Investigación \\ La vivienda rural en los pueblos de colonización
}

Manuel Calzada Pérez

Arquitecto. Colaborador honorario del Dpto. de Historia, Teoria y Composición Arquitectónicas. Universidad de Sevilla

\section{Resumen}

Este articulo tiene como objetivo encuadrar las coordenadas posibles para una valoración general de la vivienda en los pueblos de colonización. Para ello se sirve de un análisis histórico que, más allá del uso propagandístico que hizo de ella el Régimen de Franco, la enmarca en el ámbito más amplio de la vivienda racional del siglo XX y su vertiente particular de normalización de lo vernáculo. Tras un recorrido por los antecedentes previos a la Guerra Civil, se expondrá cómo por debajo del uso ideológico de la vivienda se prolongó un criterio técnico cuya base era la búsqueda de la racionalidad constructiva. A partir de aquí se apuntarán brevemente las dos orientaciones complementarias del enfoque patrimonial: un criterio que sirva de manera general a todas las actuaciones de vivienda del INC y que se fundamenta en la conservación de esa racionalidad; y un estudio concreto en cada caso para proteger otros valores estéticos, organizativos o urbanos.

\section{Palabras clave}

\section{Arquitectura}

Colonización agraria

Instituto Nacional de Colonización

Normalización arquitectónica

Núcleos urbanos

S. XX

Valoración patrimonial

Viviendas rurales

\section{Los antecedentes previos a la Guerra Civil}

Los antecedentes de la vivienda de los pueblos de colonización se encuentran en la búsqueda de vivienda salubre y económica realizada en España desde mediados del siglo XIX. Impulsados por el crecimiento urbano de aquel momento, por los avances médicos y científicos y por la precaria situación de barrios y ciudades enteras, víctimas de epidemias que terminaban por afectar a todos los estamentos (y en las cuales un hacinamiento insalubre e inmoral ponía en peligro el orden vigente), una serie de reformadores, liberales, socialistas o conservadores -estos últimos en menor medida- tuvieron que afrontar un problema que a todos afectaba. Tanto desde la legislación como desde la arquitectura se presentaron soluciones y modelos para un problema que, sin embargo, no llegó a resolverse. Nombres como Mariano Belmás -arquitecto de una primera etapa de la Ciudad Lineal, higienista, estudioso de la vivienda obrera mínima e impulsor de los barrios obreros- ayudan a entender estos primeros intentos de saneamiento.

En aquel trabajoso proceso de racionalización se pasó de las consideraciones higiénicas sobre la vivienda al debate sobre la ciudad. Era inevitable: ni la ciudad histórica podia incorporar en su tortuoso parcelario las exigencias racionales que ahora se establecían, ni los ensanches de nuevo cuño habían sido pensados para otra clase que no fuera la burguesía. Si de veras se quería una ciudad sana para todos (es decir, para los obreros, que eran los que menos la tenían) había que empezar de nuevo. Por ello se partía de un tipo residencial y se llegaba a un modelo urbano. El tipo escogido fue el de la vivienda de una o dos plantas, aislada o en hilera, que minimizara el precio de la construcción y cuyo suelo, alejado de las principales presiones especulativas por su mayor distancia a la ciudad, pudiera también ser adquirido a bajo coste. Los nuevos medios de transporte permitirian lo que hasta entonces había sido imposible: alejar la residencia y reducir el tiempo de llegada al trabajo. No se puede entender de manera independiente esta trinidad del planeamiento contemporáneo: tipo residencial, modelo urbano y sistema de transportes.

El largo debate adquirió un vigor nuevo en la década de los veinte y se prolongó durante los años anteriores a la Guerra Civil. El sector de la construcción entró en una profunda crisis como consecuencia del incremento de precios durante la Primera Guerra Mundial al que ahora se sumaba la pérdida del mercado europeo, que se había visto abastecido por España durante la contienda. Para reactivar el sector se impulsó la construcción de viviendas como primera medida que, además, servía para paliar una carestía aún sin resolver. La arquitectura europea abordaba entonces el urgente problema de la reconstrucción. Por esa razón se convocaron en- 


\section{Investigación}

La vivienda rural en los pueblos de colonización

\section{Manuel Calzada Pérez}

cuentros para técnicos en los que también participaron las administraciones públicas. El objeto era situar el tema de la vivienda mínima y la ciudad resultante en el centro de una política económica y residencial de ambiciones y alcance internacionales. Autores como López Valencia, Lacasa o Giralt Casadesus ayudaron a difundir en España los avances generados en los ámbitos anglosajón y alemán, con experiencias que aquí servirian como referencias de modernidad en nuestro debate interno.

En el centro de ese debate sobre la vivienda mínima se situó la necesidad de normalización de los elementos constructivos como base para un relanzamiento de la industria. Sin embargo, si en Europa esta necesidad se traducía en una opción técnica asociada a nuevos materiales y sistemas constructivos, en España el mayor retraso industrial y la mano de obra barata y abundante reconducirian esta vía a través de un debate paralelo de aquellos años: la tradición como fuente renovadora. De los regionalismos y nacionalismos de la década de los veinte se separaría una alternativa en que, como indica Sambricio (2000: 36):

“(...) lo popular deja de ser referencia formal, valorándose como saber capaz de ofrecer soluciones precisas a problemas concretos. Así, el estudio de las tipologías de viviendas populares se realiza paralelamente al estudio sobre el uso de los materiales o al análisis de ciertas soluciones arquitectónicas -detalles constructivos, por ejemplo, que habian sido utilizados y ensayados durante generaciones, introduciéndose en ellos cambios y lográndose por fin modelos que pudiesen ser tomados en la arquitectura económica, desde la voluntad de normalizar.

(...) Normalizar fue entonces estandarizar lo vernáculo, fue buscar una solución al problema de construir viviendas económicas e higiénicas."

En ese marco hay que reseñar una serie de iniciativas relacionadas con la vivienda mínima en España. El Reglamento de 1922 de la Ley de Casas Baratas había impuesto un mínimo volumétrico y dimensional tan generoso que mal iban a poder servir para resolver el problema de las clases obreras. Los resultados, presentes en las múltiples colonias construidas al amparo de dicha legislación, difícilmente podían equipararse, por tanto, con las propuestas de mínimo habitacional que desde el I Congreso Interaliado de Reconstrucción de Londres (1920) venian desarrollándose en el vecino ámbito europeo.

Por esa razón, y como preparación para el II Congreso Internacional de Arquitectura Moderna (CIAM) de Frankfurt -cuyo tema monográfico era la vivienda mínima- García Mercadal convocó en 1929 en España el Concurso de Vivienda Mínima. Pese a la de- cepción que supuso para el jurado el hecho de que la mayoría de las propuestas fallaran precisamente en lo esencial -que fuesen mínimas, pues se había tendido a repetir el esquema de vivienda burguesa que servía para la casa barata- el concurso si sirvió para abrir el debate desde una perspectiva que ya había previsto Lacasa (1924: 231) al afirmar que "el precio no es más que un accidente, mientras que este nuevo tipo de viviendas contiene una orientación, no sólo desde el punto de vista constructivo, sino social y ético". A partir de ahí, arquitectos como Sert o, de manera más elaborada Amós Salvador, expondrían los criterios fundamentales de esta nueva orientación pero también las disposiciones para abaratar los costes. El mismo Amós Salvador propugnó una reducción de la altura libre hasta un mínimo de 2,5 metros, cuestionando la opinión generalizada hasta entonces de que mayor altura facilitaba una más salubre ventilación de las estancias.

El Seminario de Urbanología de la Escuela de Arquitectura de Madrid, dirigido por José Fonseca y operativo hasta el estallido de la Guerra Civil, realizó una serie de estudios de curso sobre el tema de la vivienda rural que posteriormente iban a tener una decisiva influencia durante la autarquía, cuando Fonseca fue nombrado director del Instituto Nacional de Vivienda (INV). El objetivo de dicho Seminario era la sistematización y racionalización del medio rural a través de la célula mínima de habitación -la casabajo un riguroso control financiero. En la propuesta con la que obtuvo el primer premio del concurso de 1935 "La vivienda rural en España: estudio técnico y jurídico para una actuación del Estado en la materia", Fonseca expuso su método económico que, partiendo de la densidad que puede soportar una comarca, el patrimonio familiar asociado a una unidad parcelaria y el porcentaje de dicho patrimonio dirigido a la amortización de la vivienda, Ilegaba finalmente a acotar la vivienda posible resultante de aplicar tales cuentas.

Pero, además, de las cifras de la vivienda mínima se podía extraer la lectura inversa que el mismo Fonseca contemplaba: dado un mínimo residencial admisible, ¿cuál ha de ser el mínimo de parcela y de productividad? De esta manera "partiendo de las necesidades minimas (...) se calculaba la unidad de explotación que era necesaria para producir los ingresos familiares correspondientes" (Fonseca, 1940: 16). De nuevo, el estudio de la vivienda iba más allá del problema económico, pues se vindicaba un mínimo residencial irrenunciable que incluso podía llegar a afectar a la organización del territorio dentro de una maquinaria agrícola en la que había que "considerar la casa como un instrumento más de la explotación rural" (Fonseca, 1936: 13). Funcionalismo cuyo punto de partida era la unidad de explotación encarnada en la familia rural y sus requisitos habitacionales. 
1. Proyecto de viviendas rurales de los alumnos del Seminario de Urbanología. Fuente: Revista Arquitectura, año XVIII, n 1, 1936

2. Planta de vivienda para colono. Miraelrio, Jaén. Autor: José Luis Fernández del Amo. Fuente: Archivo del INC

3. Proyecto de casa para labrador en La Mancha. Fuente: INC (1954) Viviendas rurales. Madrid: INC

4. Planta de Miraelrio, Jaén. Autor: José Luis Fernández del Amo. Fuente: Revista Arquitectura, nº 192, diciembre 1974
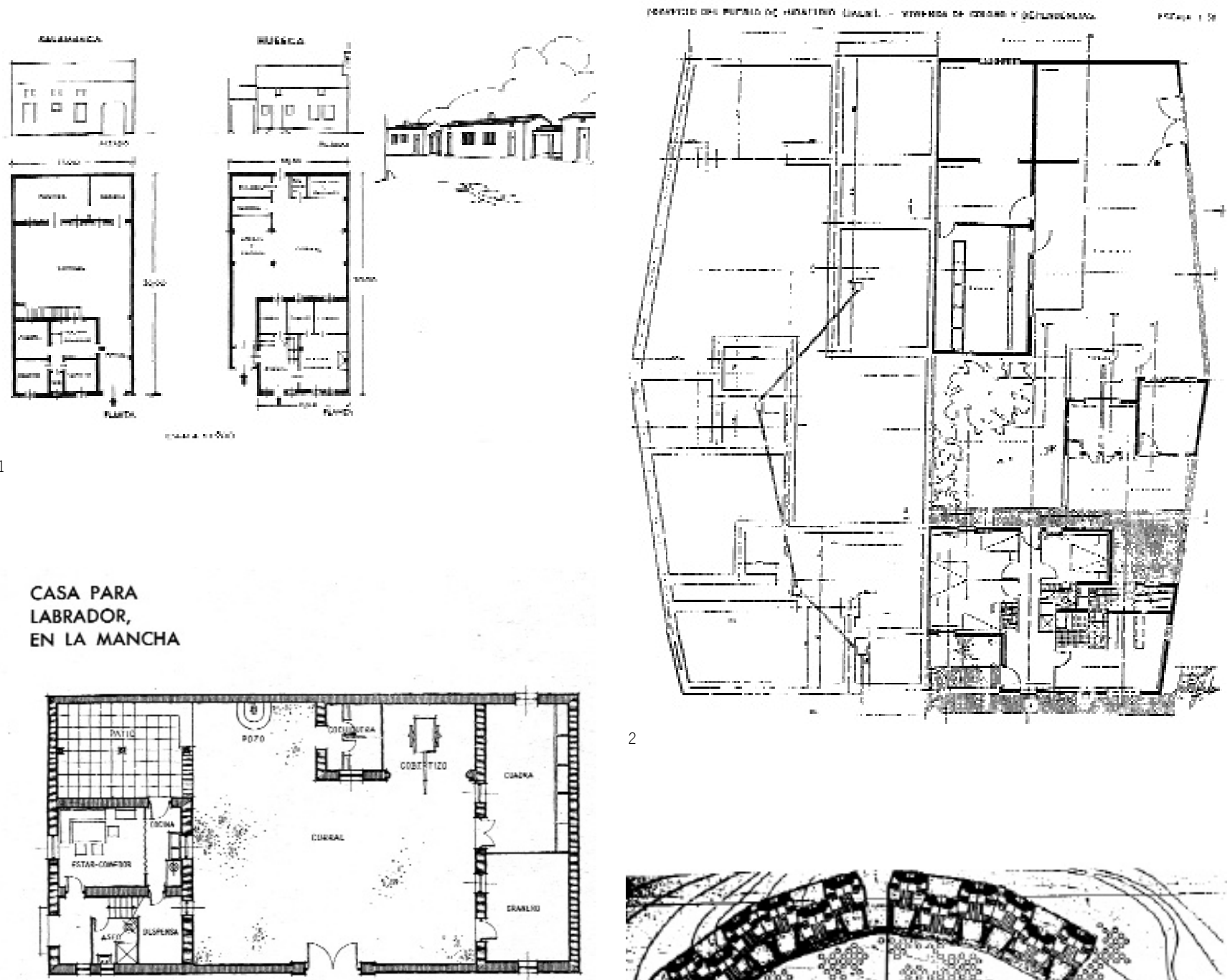

PLANTA BAJA
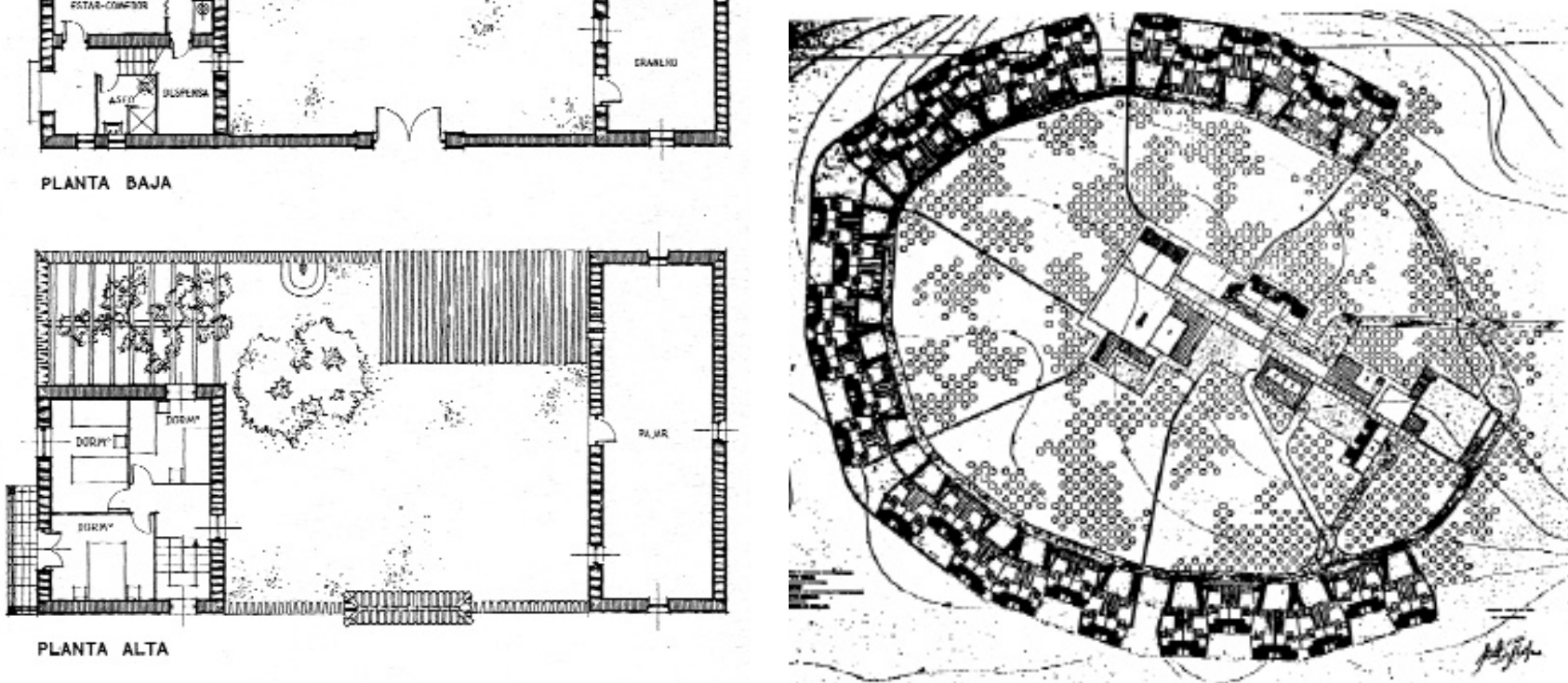


\section{Investigación}

La vivienda rural en los pueblos de colonización
5. Planta de vivienda para colono. Torre de la Reina, Sevilla. Autor: José Tamés Alarcón. Fuente: Archivo del INC

\section{Manuel Calzada Pérez}

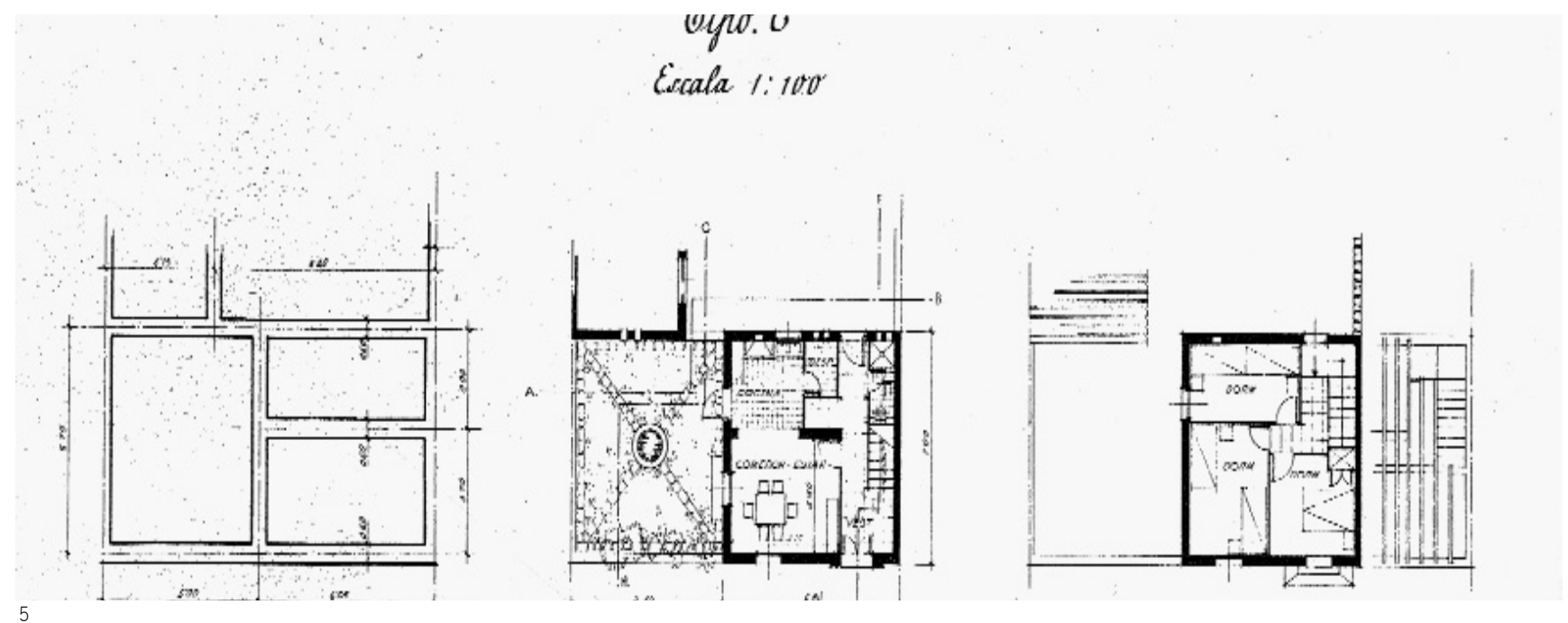

A la luz de criterios de residencia irrenunciables, el Seminario realizó una profunda revisión de la vivienda rural. Para ello se estudió la utilización de técnicas constructivas tradicionales no con un afán estilístico sino de abaratamiento de costos. Pero también se realizó un intenso examen de la organización en planta más económica y racional, de los tamaños de hueco necesarios, de las superficies, de los materiales, siempre siguiendo criterios económicos o higienistas, pero no formales. Es decir, se sometió el tema de la casa rural al criterio de racionalidad, abandonando la referencia primera a la tradición. Esto no quiere decir que los resultados formales buscaran una imagen de radical modernidad o que no hubiera alusiones a las variedades populares de cada región. Los elementos aún provenían de la tradición rural, pero en este caso no por una nostalgia bucólica sino por conveniencia constructiva y funcional (Fig. 1). La destilación del tipo realizada por el Seminario sería decisiva en la posterior labor del Instituto Nacional de Colonización (INC), de manera que, de forma indirecta, se cumplió la aspiración de Fonseca de "creación de un centro superior de cultura colonista, del que bien pudiera ser núcleo el actual Seminario de Urbanología" (Fonseca, 1936: 21).

El Seminario tomó como punto de partida en su estudio de la vivienda rural los modelos ensayados en el Agro Pontino italiano, aunque se diferenció de los mismos en dos puntos básicos: la relación vivienda-dependencias agrícolas y el modelo de asentamiento. Efectivamente, frente al tipo pontino de vivienda -que tenía en planta baja cuadras, almacenes y cocina y en planta alta el resto de estancias de vivienda, recogiendo un modo de organización firmemente anclado en la tradición rural- el Seminario optó por favorecer un criterio higienista de separación más efectiva, de modo que en la mayoría de los casos se tendía a una separación que incluso llegaba a ser total, conformando dos piezas separadas por el patio y en la que la pieza residencial no distaba tanto de otros modelos de vivienda mínima más urbanos. Modernizar suponía, pues, una homologación efectiva entre campesino y ciudadano que, a la luz escrutadora de sus criterios, no podían ser sino miembros iguales de una misma humanidad.

El segundo punto de diferencia entre Agro Pontino y Seminario era el modelo de asentamiento. El Agro Pontino optó por la dispersión de las viviendas en el territorio mientras que desde España se prefirió el pueblo o aldea -cuyo tamaño era función de la productividad y ésta, a su vez, de la distancia a las parcelas cultivables, con lo que nunca podían alcanzar una dimensión excesiva- pero que garantizaba al mismo tiempo una sociabilidad básica. Este modelo encajaba bien en el ideal de búsqueda de mínimos para la vida humana ya expuestos para la vivienda, ahora aplicados al desarrollo no de una célula familiar sino de una colectividad. Frente a unas primeras actuaciones más dispersas en la época de Primo de Rivera asociadas a la recién creada Confederación Hidrográfica del Ebro y del Guadalquivir, con fecha muy temprana y en particular en este segundo cauce se optó ya por el modelo concentrado.

La II República proseguirá esta línea de colonización mediante asentamientos concentrados, convocando en 1933 desde OPER (Obras de Puesta en Riego, el instrumento republicano para tal fin) el Concurso de Anteproyectos para la construcción de poblados en las zonas regables del Guadalquivir y Guadalmellato (Arquitectura, 1934: 267-298). Si en materia de trazado el Concurso tuvo una profunda repercusión en la labor posterior del INC, no iba a ser menor su influencia en el tema de la vivienda. Las bases de dicho concurso se apoyaron en el informe de Miguel Cavero, ingeniero agrónomo Jefe de la Sección Agronómica de 
OPER, en el que se fijaron el programa, las necesidades y las superficies de la vivienda rural. La "habitación", nombre con que se designaba a las dependencias vivideras no destinadas a uso agrícola, se componía de cocina, comedor, tres dormitorios, despensa, desván y retrete independiente pero incluido en la vivienda. El corral-patio cobraba singular importancia, pues era el espacio destinado al crecimiento de la vivienda que, con el tiempo, podría requerir nuevos locales para la explotación. Este programa no incentivaba, sin embargo, un tipo único. No sólo se permitían distintas propuestas dentro de un mismo poblado, sino que las bases exigían también otros programas residenciales para comerciantes, artesanos o maestros.

\section{Continuidad tras la Guerra Civil}

En 1939, acabada la Guerra Civil, tuvo lugar en el Teatro Español de Madrid la I Asamblea Nacional de Arquitectos, en la que las distintas facciones vencedoras expusieron los criterios para la reconstrucción del país. El primer punto para abordar fue, desde la primera conferencia -dictada por Pedro Muguruza-, y con urgencia, "mejorar el estado de la vivienda de los humildes, eliminando así una de las causas importantísimas de malestar en el Estado Español" (Muguruza, 1939: 4). Esto se habría de hacer desde (Muguruza, 1939: 5-7):

“(...) una multitud de fórmulas, de ordenaciones y disciplinas técnicas netamente españolas, netamente tradicionales, que nos corresponde recoger y aplicarlas al momento (...) Es absolutamente indispensable (...) la desaparición del concepto puramente material de "máquina de vivir" que se iba dando a las viviendas, aniquilando el concepto de hogar que les corresponde tener."

Ante esta propuesta de depuración de cualquier amago de funcionalismo, Gutiérrez Soto propuso una alternativa más desideologizada donde recuperaba el discurso disciplinar y tipológico anterior a la contienda. Ante una Asamblea exaltada en ardores de victoria, sorprende la continuidad flemática con la que dictó su conferencia sobre "Dignificación de la Vivienda", en la que no llegaba siquiera a abandonar su reputación de gran arquitecto de la burguesía. Gutiérrez Soto retomaba el debate anterior a la Guerra Civil, alineándose contra una postura de excesivo funcionalismo pero trayéndola a la mesa de debate, como si la discusión aún no hubiese quedado cerrada (Gutiérrez Soto, 1939: 50):

"Lograda la célula de vivienda tipo, éstas pueden agruparse de diferentes modalidades: en hilera formando bloques de dimensión limitada y definida, en casas unifamiliares aisladas, unifamiliares en hilera, y en las llamadas de corredor exterior o interior. Este sistema no es recomendable por la mala insolación de las habitaciones que dan a dicho corredor, por el ruido del mismo y la falta de independencia; esta disposición sólo es recomendable en tipos de vivienda para solteros, de dos piezas, o de minima familia."

Esa misma recuperación del discurso anterior a la Guerra Civil será promovida un año más tarde por José Fonseca, a la sazón jefe de los Servicios Técnicos del INV. En la II Asamblea Nacional de Arquitectos, Fonseca expuso "La mejora de la vivienda, desde el Instituto Nacional de la Vivienda". La conferencia suponía no una opinión más, sino la voz más autorizada del Régimen, por ser Fonseca el responsable técnico en materia de habitación. El INV había sido creado un año antes y, a partir de la Ley de 19 de abril de 1939 de Vivienda Protegida, sancionaba el protagonismo casi exclusivo del Estado en la materia, con la intención de evitar cualquier intención de "lucro particular" (Fonseca, 1940: 10).

Como consecuencia del Reglamento de la Ley y como primera medida del nuevo Régimen, el INV redactó en 1939 las Ordenanzas de Vivienda con un capítulo dedicado al medio rural, al tiempo que convocaba el Concurso de Vivienda Rural. El enfoque de este concurso buscaba atender a criterios de higiene y confort, variantes basadas en el clima y no en los estilos regionales. Desde las bases se requería la justificación de la vivienda a partir de un estudio económico realizado en colaboración con un ingeniero agrónomo, "para demostrar si aquello era una ficción utópica sobre el tablero o era, realmente, una cosa con firme base económica y posibilidades de desarrollo" (Fonseca, 1940: 16). Al explicar en la II Asamblea la redacción de las ordenanzas y tras analizar el tema a la luz de la amortización de intereses para el pago de la casa, como ya había hecho durante la República en su estudio de la vivienda rural, Fonseca volvió a defender la necesidad de un mínimo residencial previo a las restricciones de la economía pero que fuese en la misma dirección y que sirviese de base del texto normativo (Fonseca, 1940: 14):

"El hacer unas Ordenanzas es algo que en España es fundamental. No tenemos más inconveniente que la lucha entre la economía y el bienestar mínimo que se debe exigir a una vivienda a que yo me referi antes. Nosotros hemos intentado buscar ese confort mínimo; que las viviendas tengan un aislamiento técnico que las garantice, que se pueda vivir dentro de ellas en invierno y en verano (...) Hemos reducido alturas, pasando incluso por debajo de los 2'5 metros, que era el tope mínimo; hemos reducido, sobre todo -y esto ha sido una verdadera lucha contra el espíritu que había antes- la superficie de ventanas."

Fonseca recupera así la elaboración desarrollada por él mismo antes de la Guerra Civil y la plasma en unas ordenanzas edifica- 


\begin{tabular}{|l|}
\hline Investigación \\
La vivienda rural en los \\
pueblos de colonización
\end{tabular}

6. Vista de Vegaviana. Autor: José Luis Fernández del Amo. Foto: Kindel. Fuente: Revista Arquitectura, nº 192, diciembre 1974

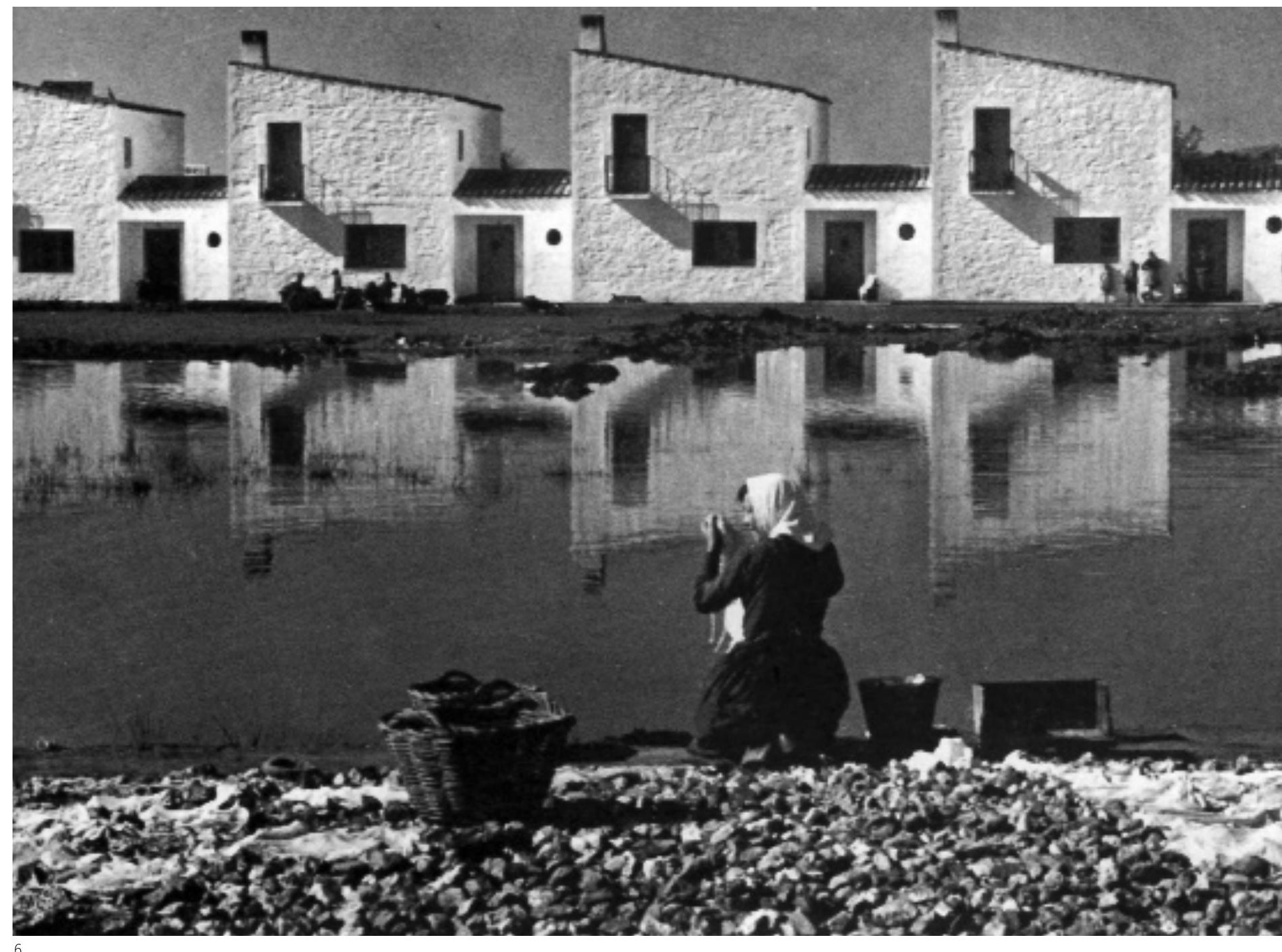

torias encaminadas a reducir a mínimos admisibles el tipo residencial. Al contrario de lo que ocurrió en el Reglamento de Casas Baratas de 1922, en esta ocasión el Estado se encargó de establecer tales mínimos de manera muy ajustada, sin duda porque en esta ocasión se hubo de encargar personalmente de la construcción de este tipo de viviendas a una escala desconocida hasta entonces. Además, dichas ordenanzas contenian "por primera vez en la legislación de todo el mundo las normas completas a que deben ajustarse las viviendas de las nuevas colonizaciones" (Fonseca, 1940: 14). Dichas normas dictaminaban no sólo el programa de la vivienda rural -tres dormitorios, cocina-comedor y retrete- sino también dimensiones, separación de dependencias agrícolas, conveniencia de uso de los materiales autóctonos, orientación de las distintas estancias y cubicación mí- nima para una correcta ventilación, además de otras disposiciones. Estas ordenanzas fueron vinculantes para el INC al ser necesarias para obtener la subvención del INV, aunque más adelante el propio Instituto contaría con independencia económica -y normativa- en este asunto.

\section{La continuidad en el INC}

El Decreto del 18 de octubre de 1939 fundaba el Instituto Nacional de Colonización con el objetivo de convertirlo en el principal instrumento de la política agraria. Para ello se redactó en diciembre de ese mismo año la Ley de Bases para la colonización de grandes zonas, en las que el Estado actuaría como apoyo subsidiario a la iniciativa privada. El 


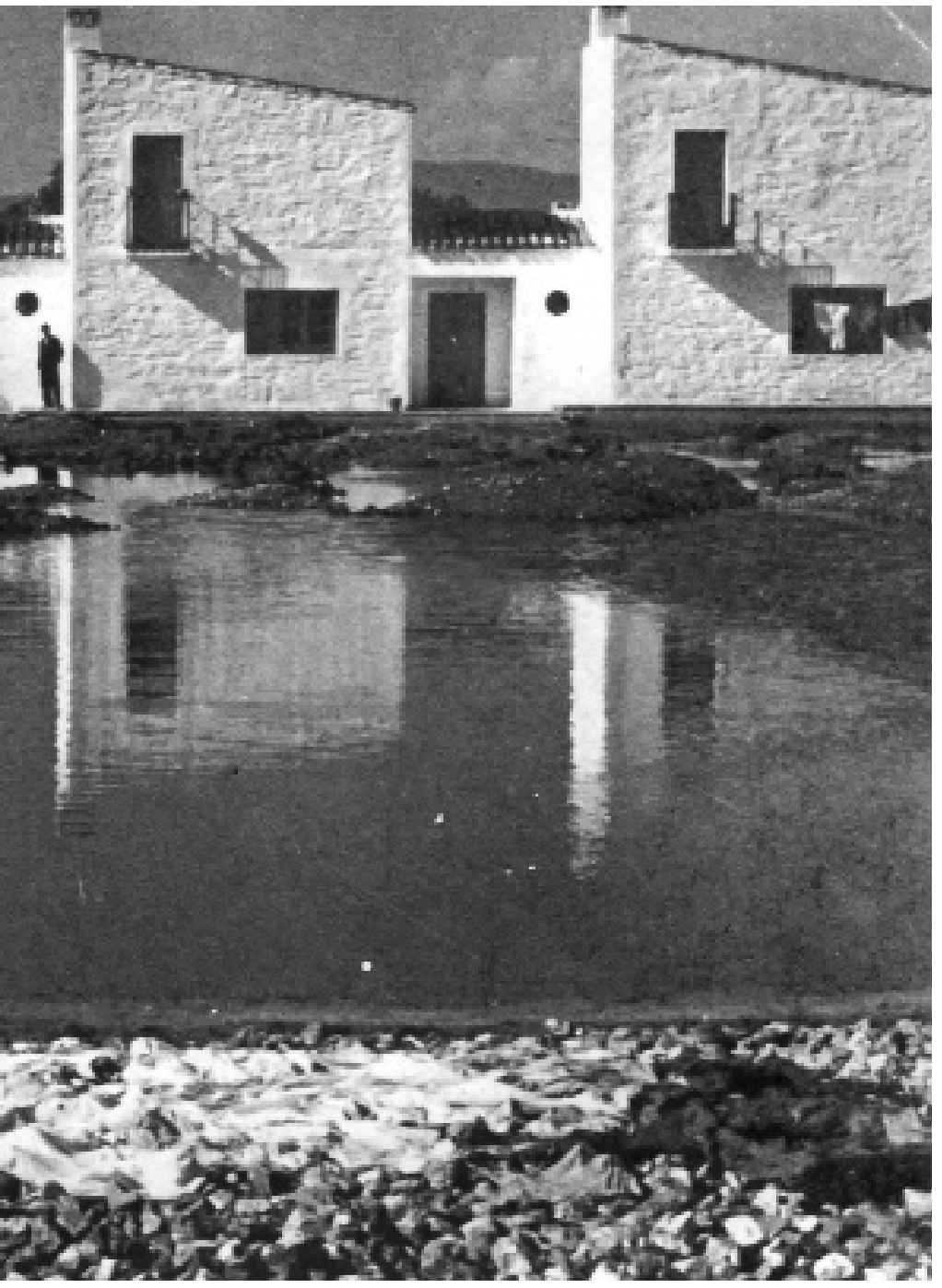

fracaso de esta iniciativa impulsaría a partir de 1946 una reforma de la legislación según la cual el Estado pasaba a asumir la responsabilidad única del proceso. Esta reforma iba acompañada de toda una reorientación técnica de influencia norteamericana que se hizo visible en los planes de desarrollo responsables del proceso y en la prioridad de fomentar el regadío (Villanueva, A. y Leal, J., 1990: 24).

La continuidad con los estudios de vivienda mínima y rural anteriores a la Guerra Civil pronto se puso de manifiesto, como admitió expresamente el vicesecretario técnico del INC, el ingeniero agrónomo Emilio Gómez Ayáu. En su estudio sobre "La importancia del coste de la vivienda rural en la economía de las explotaciones familiares de los nuevos regadios" Gómez Ayáu (1941: 21) reconocia la deuda con las bases redactadas por Cavero para el Concurso de Anteproyectos de la República. La definición de vivienda utilizada en dichas bases sirvió de punto de partida para su análisis de viabilidad económica de la vivienda rural, viabilidad requerida, por otra parte, por Fonseca. Además, el estudio se apoyaba en el "Proyecto de vivienda rural adaptado a las necesidades de un patrimonio familiar de regadio en la provincia de Sevilla", realizado en colaboración con el arquitecto Fernando de la Cuadra, premiado en el concurso de vivienda rural convocado por el INV. La bibliografía por él citada incluye tanto obras españolas como extranjeras, todas ellas anteriores al año de la victoria con la única excepción de las Ordenanzas del INV.

Un temprano ejemplo de esta continuidad se encuentra también en el proyecto del INC para la existente localidad de Malpica del Tajo y el nuevo poblado contiguo de Bernuy, obra del arquitecto Pedro Castañeda Cagigas (1944: 137-154). Dicho proyecto, ampliamente difundido por la Revista Nacional de Arquitectura (RNA), puede ser entendido como ejemplo paradigmático del enfoque racional de la vivienda, gobernada por una distribución ordenada según criterios de circulación, economía, higiene, tamaño de parcela y separación de las dependencias agricolas de las de habitación -lo que entonces se llamaba evitar la "promiscuidad de personas y animales". Como Malpica de Tajo era un pueblo ya existente, este proyecto tenía además el valor demostrativo de las ventajas de la racionalidad sobre la vivienda tradicional del lugar, construida a base de agregados, con habitaciones sin ventilar, estancias mezcladas con cuadras y escasa superficie de patio. Dichas viviendas serían sustituidas por otras ajustadas a los nuevos criterios.

También en el proyecto de Malpica hacía su aparición un criterio al que hasta ese momento no se había prestado especial atención: la alteración del tipo residencial para su distinto encaje en la trama urbana. De esta forma, se proyectaron "cuatro tipos básicos de nueva vivienda, dos de dos plantas y dos de una planta, y dentro de estos tipos generales se estudian variantes de solución, en esquina y rincones, y modificaciones de aspecto exterior" (Castañeda Cagigas, 1944: 150). El fin último de esta alteración tipológica era no una reflexión sobre el mínimo residencial o el programa, sino la búsqueda de variedad en la composición de manzanas y alzados para evitar la repetición. Esta estrategia, presente en buena parte de las actuaciones del INC, no es contradictoria con la búsqueda de normalización que tuvo lugar antes de la guerra y de la que el Instituto iba a hacer uso exhaustivo. No sólo los elementos básicos (ventanas, rejas, balcones, pero también mobiliario urbano o alumbrado público) iban a ser limitados y repetidos profusamente, sino que dado el número de actuaciones llevadas a cabo por el INC, estos mismos elementos e incluso los tipos residenciales serian utilizados en una misma zona regable e incluso adaptados de una zona a otra. Para el INC, la estandarización llegó a ser un proceso tan natural que tuvo que redoblar sus esfuerzos para evitarla. 


\begin{tabular}{|l|}
\hline Investigación \\
La vivienda rural en los \\
pueblos de colonización
\end{tabular}

7. Viviendas. Vegaviana. Autor: José Luis Fernández del Amo. Fuente AA.W.(1983) Fernández del Amo. Arquitectura 1942-1982. Madrid: Ministerio de Cultura, p. 48

8. Viviendas. Vegaviana. Autor: José Luis Fernández del Amo. Fuente AA.W.(1983) Fernández del Amo. Arquitectura 1942-1982. Madrid: Ministerio de Cultura, p. 48

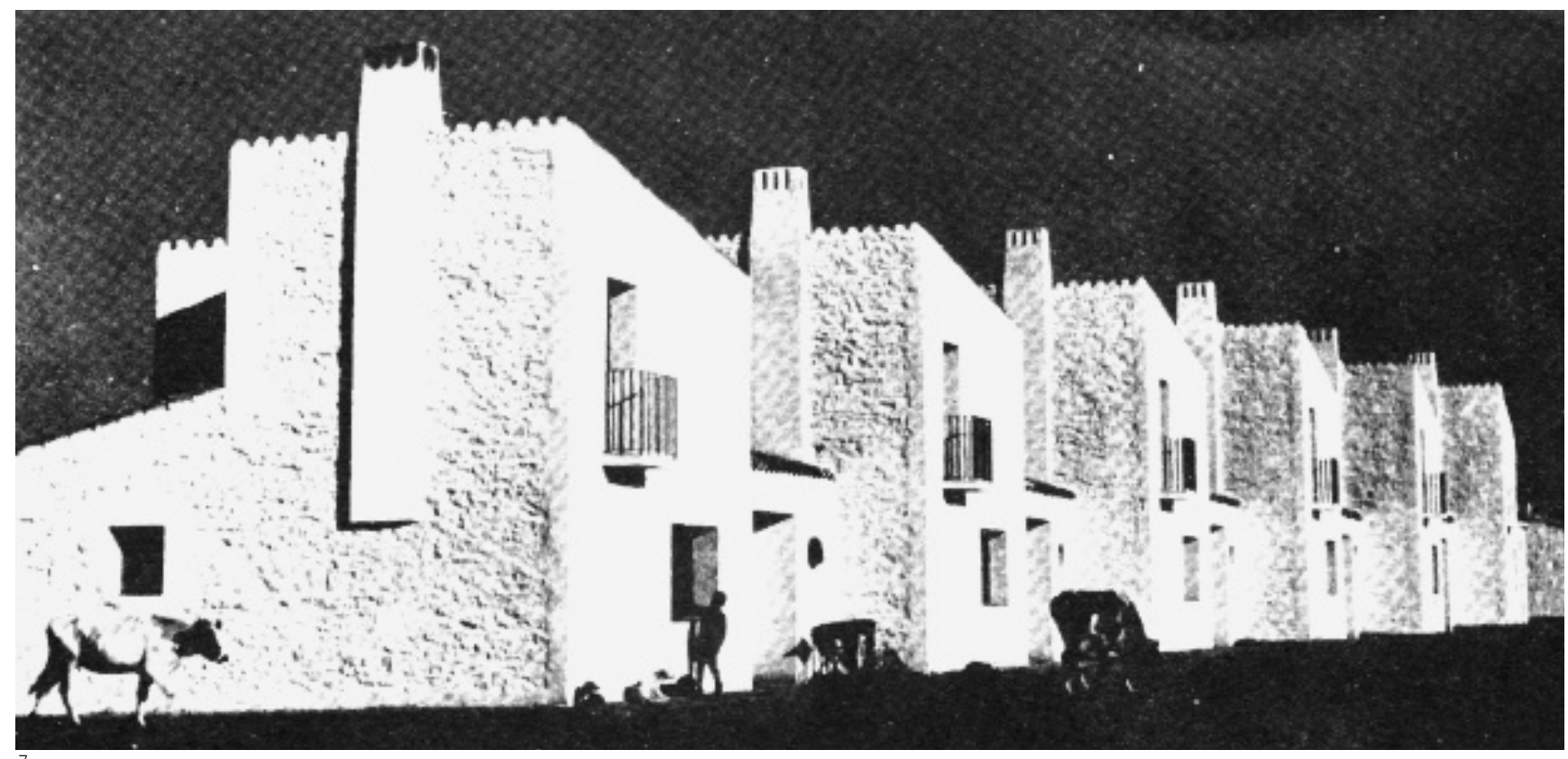

La distancia entre la realidad y el deseo de aquellos años puede encontrarse en el mismo número 28 de la RNA. Tras el citado artículo dedicado a la colonización española, la sección extranjera informaba sobre distintas actuaciones de vivienda en Europa, entre las que destacaban dos grupos residenciales construidos en Bélgica, uno en 1932 y otro en 1941 y ambos directamente vinculados a la ortodoxia funcionalista de los CIAM, tanto tipológica como estilísticamente. La misma abstracción del dibujo, que no evidenciaba su detalle constructivo, contrastaba con las detalladas secciones de las viviendas del INC, donde se reflejaban los pesados muros de carga, el forjado y las cerchas de madera, la cubierta de tablazones y teja árabe y hasta los durmientes de apoyo de las vigas. Y, sin embargo, esta atención en el detalle es un ejemplo más de cómo la tradición se empleaba como repertorio de soluciones constructivas económicas y racionales -tras un proceso de depuración y normalización- tanto o más que como revestimiento formal.

A partir de la década de los 50 el tipo de vivienda del INC ya había sido profusamente ensayado. El pueblo de Torre de la Reina en Sevilla (1951) pudo ser visto así como referencia normativa para el resto de las actuaciones. Proyectado por José Tamés, jefe del Servicio de Arquitectura desde su creación, la memoria descriptiva tuvo en este caso un valor didáctico evidente, buscando reforzar tanto el rigor económico de la propuesta como la deseable variedad del conjunto. Para ello se adjuntaba un estudio de la arquitectura popular de la zona, subrayando elementos formales y modos de agrupación urbana -callejuelas, rincones o perspectivas- que desde el proyecto se intentaban evocar. Pero además, en este pueblo puede verse también una modificación fundamental en el tipo residencial: la casa con dos puertas. Defendida como perteneciente a la tradición más arcana de los pueblos andaluces -aunque en realidad deudora del debate internacional iniciado durante los años veinte de circulaciones separadas- la casa tenía una entrada principal para peatones y una trasera para carros. Esta diferencia, que sirvió de excusa para buena parte de la evolución de los trazados de los pueblos, supuso en la vivienda un ajuste del conjunto, reforzando la autonomía de la parte vividera respecto a la agrícola y articulando un corral independiente en muchos casos del patio más urbano.

Establecido el tipo, había que combatir su homogeneidad mediante variedades regionales. Pero incluso aquí se puso de manifiesto la preponderancia de los criterios de normalización por encima de la anécdota local. La publicación del INC sobre "Viviendas rurales" de 1954 compilaba el conjunto de directrices de diseño y construcción procedentes del periodo anterior a la Guerra Civil y puestas en práctica hasta aquellos momentos. La información gráfica adjunta subrayaba dos vías posibles de transformación tipológica: la vivienda crecedera (adaptable al tamaño familiar y que ya estaba prevista en las bases de Cavero) y la variedad regional, que iba desde el cultivador agrícola de la campiña gaditana al labrador leridano. Sin embargo, los detalles de determinados elementos constructivos como ventanas o puertas -elementos cuya prefabricación era la única posible entonces- los tipos estructurales, el criterio mismo de ordenación en planta, responden a un planteamiento único, hasta tal punto que se podría incluso considerar que, más que distintos ejemplos regionales, en realidad eran variaciones sobre un tipo 


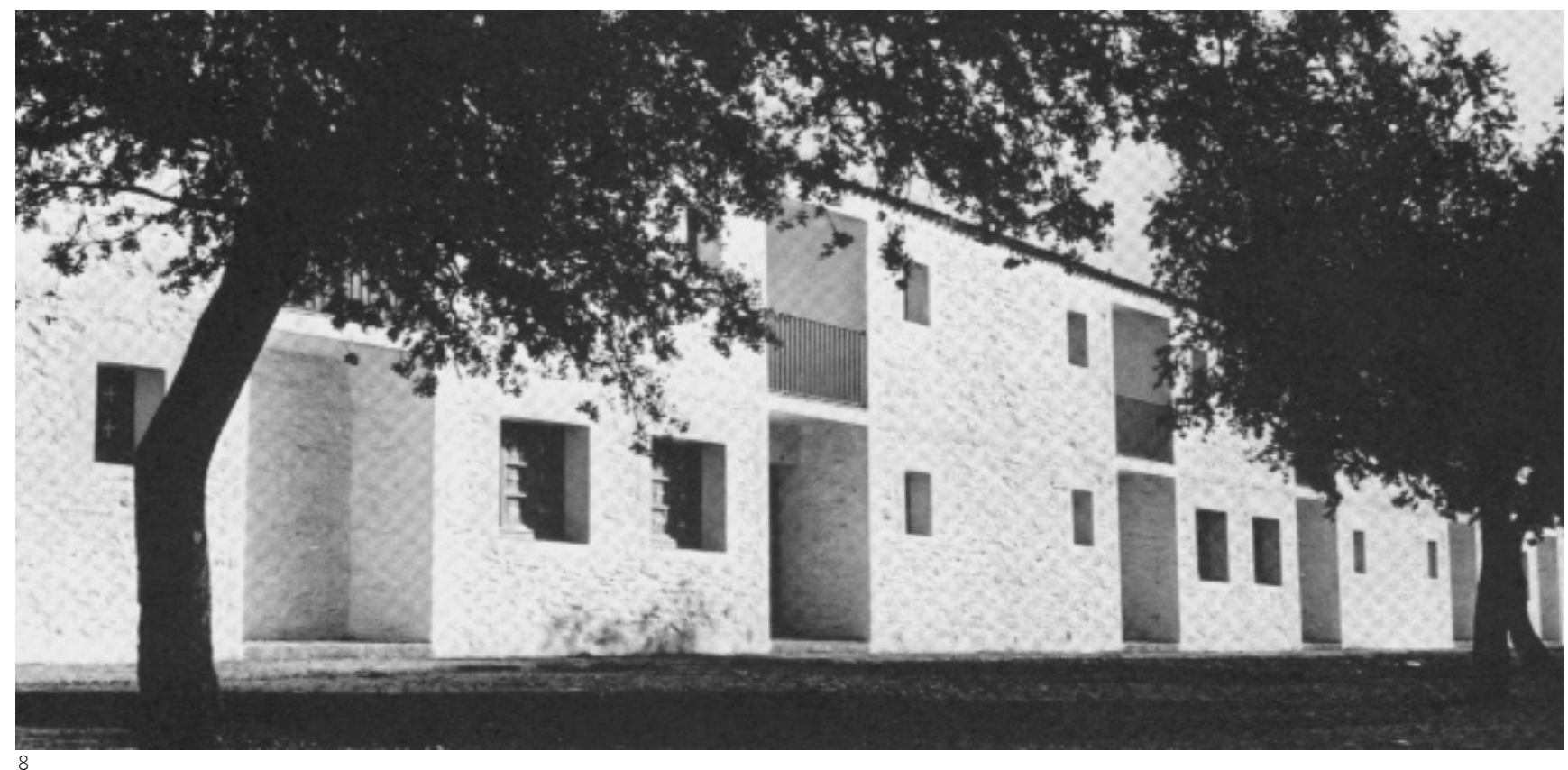

único. Es más, la casa para labrador manchego (Fig. 3) recogida en la publicación (INC, 1954: 11) respondía casi con total exactitud a una de las viviendas empleadas por José Tamés en Torre de la Reina, en Sevilla, con la sola diferencia de la reja y el balcón. Esto demuestra que esta estrategia de diseño por regiones era en realidad la coartada de un método compositivo normalizador.

\section{Un ejemplo de variaciones sobre el tipo: las viviendas de colonos de Fernández del Amo}

Para una valoración patrimonial de la vivienda de los pueblos de colonización no basta vincular su origen al largo recorrido de la vivienda racional en España, sino que es preciso prestar atención a cada uno de los pueblos de manera individual. Dada la enorme variedad de autores y el amplio periodo en que tuvieron lugar las actuaciones -más de treinta años- resulta imposible en el marco de este artículo abordar esta tarea si no es desde la perspectiva general de la normalización y racionalización de lo vernáculo. Sin embargo y sin pretender ser exhaustivos, realizaremos aquí una breve comparación entre un caso paradigmático de vivienda del INC -Torre de la Reina- y algunas de las casas realizadas por el arquitecto más reconocido del Instituto: José Luis Fernández del Amo. A través de esta comparación se mostrarán las distintas aproximaciones patrimoniales que se pueden presentar en cada caso.
Como caso paradigmático se ha seleccionado una de las viviendas proyectadas en 1952 por José Tamés para el pueblo de Torre de la Reina (Fig. 5). Como ya se ha dicho, por ser Tamés jefe de la Sección de Arquitectura, sus poblados tenían el añadido didáctico de servir de guia y ejemplo de las intenciones manifiestas desde su jefatura. Por tanto, encarnaban las directrices dictadas de manera directa en las circulares internas o indirectamente a través de la revisión de los proyectos. Esta casa de colono no puede considerarse vivienda mínima -en los pueblos de colonización también había clases y los alojamientos más reducidos, de $45 \mathrm{~m}^{2}$, quedaban reservados a los jornaleros sin parcela de labranza- pero sí una solución normalizada y racional. Las dos plantas de la casa (de 47,6 $\mathrm{m}^{2}$ cada una) separan claramente la zona de día de la de noche y permiten además un paso directo desde la casa hasta el corral, utilizable sólo por las personas. Además, un patio anexo al que se tiene acceso desde la cocina sirve de espacio abierto más doméstico frente al uso de labranza del corral. La casa es, en realidad, un tipo de vivienda pareada como los que se habian ensayado desde principios de siglo, con la adaptación a los requerimientos y la generosidad de la parcela de los pueblos de colonización. El lenguaje utilizado es de gran economía gestual salvo en el eje de acceso y en todo caso utiliza elementos de la tradición popular reinterpretados a través de un proceso de estandarización.

Frente a este ejemplo, José Luis Fernández del Amo despliega una serie de estrategias que enriquecen no sólo visualmente el conjunto del pueblo, sino también la calidad y los matices de los 


\begin{tabular}{|l|}
\hline Investigación \\
La vivienda rural en los \\
pueblos de colonización \\
Manuel Calzada Pérez \\
\hline
\end{tabular}

9. Viviendas de artesanos. Autor: José Luis Fernández del Amo. Fuente AA.W.(1983) Fernández del Amo. Arquitectura 1942-1982. Madrid: Ministerio de Cultura, p. 60

10. Viviendas de maestros. Autor: José Luis Fernández del Amo. Fuente AA.W.(1983) Fernández del Amo. Arquitectura 1942-1982. Madrid: Ministerio de Cultura, p. 61

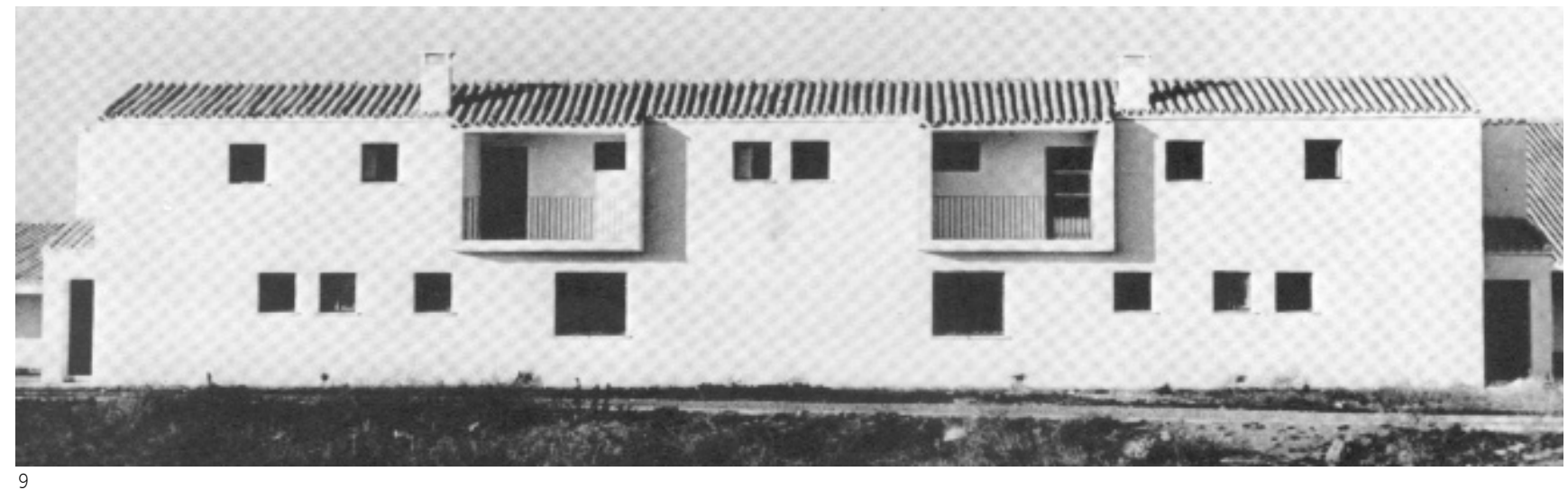

espacios vivideros. Sus proyectos de habitación, que parten de las exigencias dictadas por Tamés, se desarrollan en tres direcciones: distribución de los espacios, agrupación en la manzana y abstracción del lenguaje. El tipo, de gran sencillez aún en los ejemplos más elaborados, desplegará a través de estos mecanismos buena parte de sus posibilidades sin dejar de responder a lo exigido desde el Instituto.

Así, la casa de colono de Miraelrío (Jaén) de 1964 (Fig. 2) supone una reflexión mucho más atenta a la relación entre los espacios interiores y el exterior y los distintos grados de privacidad. Con una organización programática (separación día-noche; corredor de acceso directo al corral, módulo cocina-comedor) semejante a Torre de la Reina, pese a ocupar una única planta y con una superficie construida aún menor $\left(75 \mathrm{~m}^{2}\right)$ el autor se sirve de los patios para articular la vivienda de modo muy distinto en un pueblo que, en sí, no es sino un gran espacio comunitario. Como si quisiera agotar las posibilidades de este elemento en sus modestas viviendas, Fernández del Amo incorpora un pequeño patio de acceso, otro de uso privativo de cocina y lavado de ropa, uno tercero ajardinado para solaz de la familia y, por fin, el corral, en una secuencia simple, casi inadvertida ante el gesto formal -aunque necesario- del hexágono de la parcelación, pero de enorme eficacia compositiva. De esta manera, un tema principal -el patio- atraviesa transversalmente las distintas escalas del proyecto desde la planta del pueblo al diseño de las estancias y sirve además para conseguir agrupaciones de manzana inesperadas y novedosas (Fig. 4). La reflexión sobre la agrupación de viviendas en Fernández del Amo es una de sus aportaciones más singulares al diseño de los pueblos y tiene tanto de investigación de trazado como de prolongación de la vivienda. Y todo esto utilizando un lenguaje popular de gran abstracción, paradoja ésta de difícil equilibrio. Frente al irónico regocijo de Alejandro de la Sota en Esquivel -donde la recreación del lenguaje popular se hace a través de un ejercicio de manifiesta compla- cencia- Fernández del Amo consigue una depuración formal extrema. Y esto lo logra mediante la superación del propio elemento popular, que pasa inapreciado ante un orden de rango superior, regido por la repetición y la alternancia, el empleo violento del claroscuro y de la sombra, la sucesión de huecos, masas y vacios y la extrañeza de algunos elementos constructivos que en su mano adquieren una naturaleza levemente distinta, lo suficiente para pasar desapercibidos sin evitar la extrañeza -qué distinto, por ejemplo, el expresivo uso que hace de los paños de tejado, del recorte de los aleros-. Un lenguaje en el seno de una rigurosa composición que admiró al pintor Canogar, quien afirmaba (AA.WV. 1983: 33):

Y es que José Luis Fernández del Amo es, él también, un plástico: un plástico de la arquitectura. Su bellísimo pueblo, Vegaviana, quedó fojado en mi memoria; poesía plástica, planificado y construido con el rigor y la sensibilidad de un cuadro de Mondrian. Artesanía del espacio y, como él mismo diría: "expresión de la materia hecho objeto artístico".

\section{Valoración patrimonial: breve apunte para la práctica}

La valoración de la vivienda de los pueblos no puede ser, como se deduce de todo lo antedicho, un acto uniforme e igual para todos los casos. La diversidad de ejemplos, de etapas y de calidades hace necesario un examen riguroso que corresponde realizar a cada municipio y cuyo control último está en manos de la Comunidad Autónoma. Sin embargo, la posición defendida en este artículo sostiene un doble criterio, general y amplio para todos los casos y particular en el detalle pormenorizado.

El criterio general es el criterio de la racionalidad que desde el Instituto Nacional de Colonización se persiguió en todo momen- 


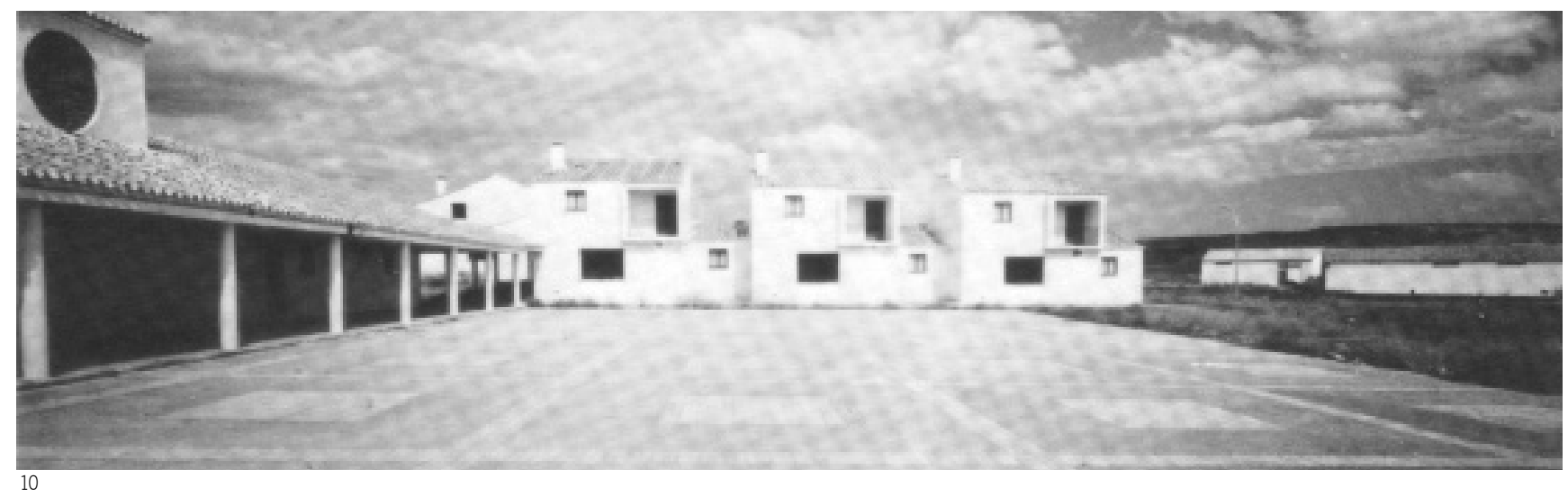

to. Esta racionalidad está vinculada, en definitiva, al proyecto moderno, y ha quedado tan profundamente integrada en nuestra cultura urbanística -tamaños mínimos, ventilación, soleamiento, exigencias de habitabilidad irrenunciable- que más parecería vinculada a una ordenanza general que a una especial protección de indole patrimonial. La realidad, sin embargo, demuestra cómo los cambios en las viviendas, más allá de la alteración de determinados elementos formales, han afectado profundamente a la racionalidad del conjunto, invadiendo patios, añadiendo crujías, clausurando ventanas y cegando estancias enteras. Evitar estos deterioros de la vivienda desde la perspectiva patrimonial supone un reconocimiento a una cultura -la de la racionalidad contemporánea- que sigue vigente y operativa. Al contrario de lo que defiende Italo Calvino (1994: 38) -para el que la iniciativa por conocer, registrar y en última instancia preservar las manifestaciones culturales populares estuvo asociada desde los orígenes de las disciplinas involucradas a la certeza de su próxima defunción- se propone aquí una consideración del patrimonio de la modernidad como realidad vigente y operativa.

Por supuesto, más allá de esta protección mínima en la que el acuerdo puede ser mucho más amplio, cada caso concreto exigirá posteriormente un juicio particular ¿Qué sentido tendría, por ejemplo, proteger la uniformidad estilística de determinadas agrupaciones de vivienda? Esta uniformidad era fruto de una necesidad económica y sólo en algunas ocasiones se hizo un uso magistral de ella como creación estética. Pretender conservar integramente los rasgos formales y repetitivos de estos pueblos puede entenderse tanto como una vindicación identitaria cuanto como un fundamentalismo estilístico que no consigue entender el implacable paso del tiempo. El papel de los especialistas consiste en subrayar, esclarecer, incluso denunciar, pero han de ser las comunidades afectadas las que se sientan interpeladas a enjuiciar su propio patrimonio. Sólo así tiene sentido su protección.

\section{Bibliografía}

ARQUITECTURA (1936) Concurso de anteproyectos para la construcción de poblados en las zonas regables del Guadalquivir y el Guadalmellato. Arquitectura, v. XVI, nº 10, 1936, pp. 267-298

AA.VV. (1983) Fernández del Amo. Arquitectura 1942-1982. Madrid: Ministerio de Cultura, 1983, p 33

CALVINO, I. (1994) Collezione di sabbia. Milano: Oscar Mondadori, 1994 (ed. 2002)

CAStañedA CAgigaS, P.; PÉREZ NARANJO, V. (1944) Proyecto de Colonización de la finca "Valdepusa". Ordenación del pueblo de Malpica de Tajo y de un nuevo núcleo. Revista Nacional de Arquitectura, v. III, n² 28, 1944, pp. 136-151

FONSECA, J. (1936) La vivienda rural en España: estudio técnico y jurídico para una actuación del Estado en la materia. Arquitectura, v. XVIII, n 1, 1936, pp. 12-24

FONSECA, J. (1940) La mejora de la vivienda, vista desde el Instituto Nacional de la Vivienda. En II Asamblea Nacional de Arquitectos. Madrid: sin editor. Conservada en la biblioteca del COAM con el expediente $n^{\circ} 3185,1940$, pp. 5-27

GÓMEZ AYAU, E. (1941) Importancia del coste de la vivienda rural en la economía de las explotaciones familiares de los nuevos regadios. Madrid: INC, 1941

GUTIÉRREZ SOTO, L. (1939) Dignificación de la vivienda. En I Asamblea Nacional de Arquitectos. Madrid: Servicios Técnicos de FET y de JONS, 1939, pp. 39-56

INC (1954) Viviendas rurales. Madrid: INC, 1954

LACASA, L. (1924) Un libro alemán sobre casas baratas. Arquitectura, nº 64, 1924, pp. 231-232

MUGURUZA, P. (1939) Ideas generales sobre Ordenación y Reconstrucción Nacional. Madrid En I Asamblea Nacional de Arquitectos. Madrid: Servicios Técnicos de FET y de JONS, 1939, pp. 3-13

SAMBRICIO, C. (2000) La normalización de la arquitectura vernácula. Un debate en la España de los veinte. Revista de Occidente, n² 235, 2000, pp. 21-44

VILLANUEVA PAREDES, A.; LEAL MALDONADO, J. (1990) La planificación del regadio y los pueblos de colonización. Madrid: M.A.P.A., 1990 